\title{
A new stage of our journal
}

\section{A truly multimodal and international platform for the study of gastric cancer}

\author{
Yuko Kitagawa ${ }^{1}$
}

Published online: 1 December 2015

(c) The International Gastric Cancer Association and The Japanese Gastric Cancer Association 2015

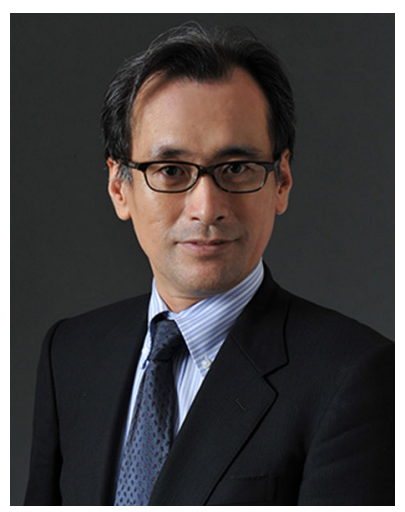

Gastric Cancer was launched in 1998 as a unique journal focusing only on the study of gastric cancer. Although the journal was established as the official journal of the International Gastric Cancer Association and the Japan Gastric Cancer Association, how many of us could have imagined that Gastric Cancer would become such a prestigious journal with a high impact factor? On this special occasion, I would like to express my special gratitude to the founders and all the contributors to our journal, including editors and reviewers, and especially to
Dr. Takeshi Sano, who is the real father of Gastric Cancer, as you already know.

Gastric Cancer received its highest impact factor of 4.828 in 2013, and since then the number of submissions has increased annually and the quality of published articles has improved significantly. As for the high impact factor, we have to recognize the contribution of articles on gastric cancer classification and therapeutic guidelines. On the basis of this achievement, now worldwide investigators of gastrointestinal malignancies have realized that Gastric Cancer is one of the best target journals in this field.

Since the 2015 International Gastric Cancer Congress in Brazil, Prof. Giovanni de Manzoni has joined us as a coeditor-in-chief of our journal. With his strong leadership in the Western Hemisphere, Gastric Cancer will enter a new stage as a truly multimodal and international platform for the study of gastric cancer. On this special occasion, I believe that we must update the requirements for our journal to make it an even more strictly controlled, firstclass scientific publication. I am truly looking forward to working with Prof. Giovanni de Manzoni and all the contributors to our journal.

Yuko Kitagawa

kitagawa@a3.keio.jp

1 Department of Surgery, Keio University School of Medicine, Tokyo, Japan 